\title{
A predischarge unit in a long-stay hospital for subnormality
}

\author{
M C LIU, M W HUGHES, L M ASHTON
}

British Medical fournal, 1976, 2, 921-922

\begin{abstract}
Summary
A newly built residential ward in the grounds of a longstay mental subnormality hospital was converted into a predischarge unit to cater for those patients who could probably be discharged after some special training. So far 31 residents have been trained over the past two years; $18\left(5^{\circ}{ }_{0}\right)$ have been discharged to community residences, and five were waiting for discharge. The high success rate shows the value and usefulness of a predischarge unit in a long-stay hospital, and also shows that a purpose-built building is not necessary so long as the staff have the initiative and will to succeed.
\end{abstract}

\section{Introduction}

In 1970-1 a survey at Monyhull hospital showed that $10^{\circ}$ of the inpatients no longer needed to be there. They were accordingly discharged to community accommodation or their own homes. Over half the rest of the residents were aged over 50, and over $20^{\circ}{ }_{0}$ were over 60 . Some had been at Monyhull for over 60 years and the average stay was 22 years. Over $10 \%$ had no relatives, and another $20^{\circ} \%$ had no or very little contact with their relatives.

Apart from some of the older residents who had originally been admitted from the Poor Law institutions, not necessarily because of low intellect, and a few with behaviour disorders,

Monyhull Hospital, King's Norton, Birmingham B30 3QB

M C LIU, MD, FRCPSYCH, consultant psychiatrist and postgraduate clinical tutor

$M$ W HUGHES, BsC, MB, medical assistant

L M ASHTON, BA, social worker most of the residents suffer from severe mental subnormality and are physically handicapped. Nevertheless, some residents have the potential and are willing to work for their discharge. We thought that if they were given training and practical social education, these long-stay residents, who were originally considered unsuitable for community care, could probably be discharged to community residences for care and some kind of employment.

\section{The unit}

Hence a newly built 20-room residential ward next to a hospital hostel was converted into a 17-bed predischarge unit. The other three rooms were used as an office, a kitchenette for domestic science training, and a rest room, where television, radio, and a record player were provided. The rest room was also used for discussions and group meetings.

These three converted rooms are far from ideal and meals and washing facilities have to be shared with the main hostel. Nevertheless, we thought that so long as we had conviction and enthusiasm we would succeed. We describe here the unit's policies and the outcome of the first two years.

\section{Staff}

The predischarge unit is run by a multidisciplinary team. A psychiatrist and the medical staff look after the residents' health and hold weekly group therapy sessions. Together with the social workers (who also liaise with social services departments to find suitable accommodation after discharge), the nurses teach the patients social skills, and the education officer helps in teaching them to read and write. The nurses also arrange evening classes for them. Psychologists assess the patients initially and before discharge, and the occupational therapists play a part in developing the patients' social and leisure activities. The whole team meets weekly or fortnightly.

\section{Policy}

\section{SELECTION}

Initially all the ward staff and occupational therapists who knew the residents well were asked to evaluate the suitability of certain patients 
for training. Special care was taken to determine the patients' manual dexterity, co-ordination, and motor skills; their tolerance for routine jobs; their personalities and interpersonal relationships; their power to communicate; their response to authority; their motivation; their efforts towards an independent existence; and any special problems.

At present only women aged 16 and over are being selected for training, although we hope to include men when we have more staff. The patients spend one to two years in the unit, depending on their needs. Generally, those selected are those with the highest potential and motivation and a desire to live in the community. They have to (a) have a stable and sociable personality, $(b)$ be capable of holding down a job (or if they have retired, be suitable for part III accommodation or geriatric units), $(c)$ be independent and able to attend to their own needs and affairs.

\section{TRAINING}

Their training covers three broad areas.

Basic education-Residents learn to sign their names and to read and write simple letters and documents. They are taught to manage money, tell the time, and be punctual. They are also encouraged to become interested in day-to-day affairs and local news and to attend further education evening classes. Whenever possible they are taught how to use public libraries.

Social education includes outside visits. The aim here is to encourage the residents to obtain general social knowledge, to find things out, and to learn by "doing." They are taught the traffic regulations and learn how to use public transport. They are also taught how to use public and private telephones and how to shop. They learn about the Post Office and its various functions, including banking.

Working discipline includes punctuality, manners and courtesy, and personal appearance and hygiene. A high standard of hygiene and appearance is demanded so that the residents can prepare themselves for society's demands.

They also learn cooking and domestic skills and about leisure activities. These include swimming, dancing, sight-seeing, gardening, and attendance at evening classes to learn music, art, etc. Each patient also receives psychotherapy; various topics are discussed and patients are counselled about their problems.

\section{DISCHARGE}

The unit has worked closely with the community social services department, and after training residents may be sent home or placed in living-in jobs, community hostels, part III accommodation (for those in need of care and attention), geriatric units, or lodgings and group homes.

\section{Patients trained in unit}

During the past two years 31 residents have been selected for training in the unit. Because of staff shortages the unit has been able to take only 13-14 residents at a time.

Before admission to the unit, the patients' average stay in hospital was 30 years. Their ages ranged from 23 to 61 years (mean 40 years), and they stayed at the unit from one month to 23 months (mean 10 months). Their intelligence quotients varied from 30-73 (mean 50). Ten of the 31 patients suffered from some behaviour disorder as well as their mental subnormality. Seven suffered from subnormality and social inadequacy, seven from epilepsy, four from psychotic disorders, two from personality disorders, and one from Down's syndrome and some behaviour problems. Nevertheless, with the treatment and social and educational training they had received in hospital their condition had improved so much that we thought that, with some special training, they might still have a chance of returning to live in the community.

\section{TRAINING}

Timetables for individuals and small groups of residents were drawn up daily or weekly to provide for specific needs. The day staff were responsible for training during weekly working hours. The nursing staff were also responsible for weekend training and the night staff for their evening training. Just as working people do on returning home, the residents prepared their tea or evening meal, washed their dirty clothing, and put out clean clothes for the next day. In the morning they were trained to get themselves ready for the day's work; special attention was paid to cleanliness and appearance so that they would look presentable for the day's programme.

At times the training programme was a great challenge and required patience, tolerance, and understanding from the staff. The staff would have liked to have given the residents as much freedom in their social activities as possible, but the residents had to know how to conform to the standards expected of them by society.

\section{OUTCOME}

Of the 31 residents five were returned to the main hospital because of their unsuitability, and 18 were discharged to community accommodation. The hospital social worker continued to give advice and to provide supervision until the patient was well settled and happy in her new environment. Then the appropriate social worker for the area in which the patient was placed took over supervision and support. This usually happened about six months after discharge.

Twelve of these residents were discharged to community hostels and four to part III accommodation, one went to an old people's home as a domestic worker, and another was transferred to a hospital for special rehabilitation. Ten of the 12 in community hostels got jobs and two attended a community adult training centre.

Five of the 12 residents still in the predischarge unit are waiting for discharge. One has returned to the hospital because of her behaviour problems, but she might be transferred back to the unit once her behaviour has improved.

\section{Discussion}

We have achieved a discharge rate of $58 \%$ from the predischarge unit. Without training these residents would probably have had no chance of re-entering the community. Because of staff shortages and the numbers of patients we could not carry out specialised training on the wards. We thought also that a unit away from the main building, even though not purposebuilt, would provide a more appropriate environment, reducing the patients' reliance on the main hospital.

We accepted that some residents would have to go to sheltered accommodation on discharge, but the extra training was aimed at making them feel that they would be useful citizens. In some cases the stay in a hostel was seen as a stage in the patient's gradual re-entry into society. Four of the 12 residents who were discharged to local authority hostels are now in minimal care units, two are in group houses, and one is in a flat of her own.

The unexpectedly successful result was due to the enthusiasm and hard work of the staff, together with the continued encouragement and the co-operation of outside services. Thus our ultimate aim of integracing the mentally retarded into the community is being achieved.

We are grateful for the support of the hospital authority and other hospital staff; for the help of the community social services; and for the programme arranged by the Bournville College of Further Education.

$A$ woman has been satisfactorily treated for three-and-a-half years with lithium carbonate for a manic-depressive illness. She has responded so well that she is about to be taken off this drug. She married just over a year ago: how long should she wait after coming off the lithium before she contemplates having a baby?

From the point of view of the presence of lithium in the body and possible effects on the fetus, it is best to wait at least one month to ensure that lithium has been excreted. In relation to the prophylactic effect of lithium that will cease when the salt is withdrawn, the time allowed to elapse depends on the history of the affective illness before lithium was started. If the past episodes of depression or elation were well spaced there is no point in waiting, but if attacks have been closely spaced it is usual to wait for a minimum of six months to assess whether relapse without lithium is likely. This would no doubt be decided, however, in consultation with the psychiatrist familiar with the previous history and management. 